A MICRO LEVEL ANALYSIS OF VIOLENT CONFLICT

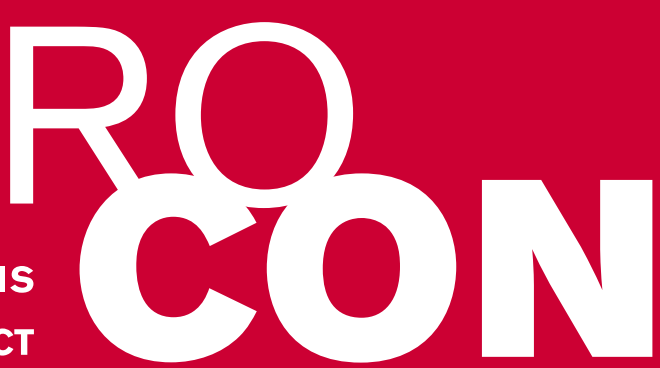

Who Engages in Water Scarcity Conflicts? A Field Experiment with Irrigators in Semi-arid Africa

MICROCON Research Working Paper 31

Els Lecoutere, Ben D'Exelle, and Bjorn Van Campenhout

August 2010 
Correct citation: Lecoutere, E., D’Exelle, B. and Van Campenhout, B., 2010. Who Engages in Water Scarcity Conflicts? A Field Experiment with Irrigators in Semi-arid Africa. MICROCON Research Working Paper 31, Brighton: MICROCON

First published in 2010

(C) Els Lecoutere, Ben D'Exelle, and Bjorn Van Campenhout 2010

ISBN 9781858649420

For further information, please contact:

MICROCON: A Micro Level Analysis of Violent Conflict, Institute of Development Studies at the University of Sussex, Brighton BN1 9RE

Tel: $+44(0) 1273872891$

Email: info@microconflict.eu

Web: www.microconflict.eu 


\title{
MICRON
}

\section{Who Engages in Water Scarcity Conflicts? A Field Experiment with Irrigators in Semi-arid Africa ${ }^{1}$}

\author{
Els Lecoutere $^{2}$, Ben D’Exelle ${ }^{3}$, and Bjorn Van Campenhout ${ }^{4}$
}

MICROCON Research Working Paper 31

July 2010

\begin{abstract}
Does water scarcity induce conflict? And who would engage in a water scarcity conflict? In this paper we look for evidence of the relation between water scarcity and conflictive behavior. With a framed field experiment conducted with smallholder irrigators from semi-arid Tanzania that replicates appropriation from an occasionally scarce common water flow we assess what type of water users is more inclined to react in conflictive way to scarcity. On average, water scarcity induces selfish appropriation behavior in the experiment which is regarded conflictive in the Tanzanian irrigator communities where strong noncompetition norms regulate irrigation water distribution. But not all react to water scarcity in the same way. Poor, marginalized, dissocialized irrigators with low human capital and with higher stakes are most likely to react with conflictive appropriation behavior to water scarcity. Viewed a political ecology perspective we conclude that circumstances in Tanzania are conducive to resource scarcity conflicts. Water scarcity and water values are increasing. Water governance institutions entail exclusionary elements. Moreover, a higher likelihood to react in a conflictive way to water scarcity coincides with real economic and political inequalities which could form a basis for mobilization for more violent ways of competing for scarce resources.
\end{abstract}

\footnotetext{
${ }^{1}$ We acknowledge financial support from MICROCON, IDPM (University of Antwerp), Ghent University and FWO. We are grateful to Incomet 2001, the Mufindi district council and Charles Kyando. We thank participants of the MICROCON Workshop 2010 for useful comments.

${ }^{2}$ Ghent University, Department of Third World Studies, Conflict Research Group. Corresponding author. Email: Els.Lecoutere@UGent.be.

${ }^{3}$ University of East Anglia, School of International Development.

${ }^{4}$ University of Antwerp, Institute of Development Policy and Management.
} 


\section{Introduction}

Conflicts over water have been the centre of attention for some time. Not only has a future of inter state water wars been forecasted, also the internal, civil conflicts that mark the last decennia have been linked to an increasing scarcity of natural resources like water or cropland (Starr 1991, UNDP 2006, Homer-Dixon 1994, Kaplan 1994, Le Billon 2001, Welsch 2008). While the literature provides bits and pieces of the answer on how resource scarcity and conflict relate, there is no evidence of the relation between resource scarcity and the individual predisposition for conflictive behavior. This study will provide such evidence by making use of a framed field experiment, conducted with irrigators from semi-arid Tanzania, which replicates water appropriation dilemmas in common water flows under circumstances of water scarcity. We assume that water users who are more likely to react to scarcity in a conflictive way in the experiment may also be more inclined to resort to more violent ways of competing for scarce resources if other circumstances conducive to conflict would arise. It is therefore particularly relevant to look for behavioral evidence of the relation between water scarcity and conflict and to assess who is more likely to engage in water scarcity conflicts. Evaluating these findings from a political ecology perspective allows gauging the potential of water scarcity conflicts in this setting.

\section{Literature on the relation between resource scarcity and conflict}

The relation between resource scarcity and conflict has been amply debated in the literature. We give an overview. The environmental security literature states there is a causal relation between scarcity of natural resources and violent conflict and predicts resource scarcity conflicts are on the rise ${ }^{5}$. Increasing scarcity of resources is expected not only to provoke internal or interstate conflicts, but also to induce large population movements which will feed group identity conflicts. It may deepen economic deprivation and disrupt social institutions and contribute to deprivation conflicts (HomerDixon 1994). Besides, resource scarcity is more likely to lead to violent conflict if an inability to solve

\footnotetext{
${ }^{5}$ Natural resources like water, cropland, forests and fish are diffuse, not lootable and renewable resources with a low marginal value but a high total value because they are essential for humans and the biosphere. When it concerns this type of resources, scarcity makes its value (Le Billon, 2001).
} 
complex problems aggravates grievances and erodes the moral and coercive authority of government (Homer-Dixon 1999). Yet, the environmental security literature has been criticized for being too deterministic and a-political, for generalizing too much and for being based on anecdotal evidence which suffers from a selection bias as it is mainly based on cases where resource scarcity and conflicts coincide (Gleditsch 2001, Le Billon 2001).

The common pool resource (CPR) literature also deals with the relation between resource scarcity and conflict. Actually, it has proven that institutions hold the potential to overcome distributive conflicts and overuse (Ostrom 1990). The CPR literature, however, is criticized for oversimplification as it sees scarcity as a likely cause of competitive struggles if unconstrained by proper institutions. But because of its focus on cooperation it does not suffer from selection bias (Turner 2004). For instance, in the politically instable Somali Region in Ethiopia where drought causes environmental scarcity, farmers and pastoralist have a non-violent relationship because farmers and pastoralists have adopted different institutions for sharing scarce resources (Bogale and Korf 2007). Another example involves the relatively peaceful sharing of increasingly scarce salmon stocks in the Coastal Salish Fisheries in the US with the aid of an adapted and flexible set of institutions for governing fish appropriation (Singleton 2007).

Apart from case studies on cooperation or conflict in circumstances where CPR are scarce, this strand of literature also includes analyses of CPR users' behavior based on laboratory or field experiments (e.g. Cardenas and Carpenter 2004, Cardenas 2003). Few experimental studies however look at the effect of resource scarcity on behavior. Exceptions include Rutte et al. (1987) who conducted an experiment with students using a one shot game simulating sequential CPR appropriation and who found that subjects harvested less from the resource in scarcity than in abundance conditions, especially when scarcity was nature-induced. De Kwaadsteniet et al. (2006) conducted an experiment with students and found that subjects are guided by the equal division rule if there is resource size certainty. But 'proself' oriented subjects appropriate more 'prosocially' oriented ones. Osés-Eraso and Viladrich-Grau (2007) use an experiment with students in which subjects first choose between extracting or not from a CPR stock after which the remaining resource units are shared. Resource 
scarcity is replicated by reducing the initial resource stock. They show that appropriation levels diminish with increasing CPR scarcity which they attribute to subjects' concern for resource scarcity.

Political ecology scholars however argue that causes of resource conflicts may be much more complex than competitive struggles over scarce resources ${ }^{6}$. Resource conflicts may be rooted in history, broader social tensions or disagreements over ethical issues like proper resource use. Moreover, the forms of access to and control over resources that depend on culture, social construction, power and political economy may shape processes of exclusion or engender competitive struggles (Le Billon 2001, Peluso and Watts 2001, Turner 2004). The Kilosa killings in Tanzania, for instance, cannot be solely explained by a competitive struggle over scarce resources between farmers and pastoralists (Benjaminsen et al. 2009). Underlying is an historical and ongoing spatial and political marginalization of pastoralists in favor of farmers. Additionally, a culture of clientilism and corruption have eroded trust in the local government and have reduced the willingness of local judiciary and police to prevent conflicts.

The political ecology literature urges to take other contextual factors into account when studying the relation between resource scarcity and violent conflict. This brings us to the literature that concentrates on civil conflict and its drivers. First, marginalization contributes to a higher incidence of civil conflict and a higher likelihood that individuals or groups will participate in violence. Groups may be mobilized to join in violence on grounds of real or constructed group inequalities. This is most effective if differences in economic opportunities - such as differential access to water - or political marginalization coincide with cultural, ethnic or religious differences (Stewart 2000). Exclusion from access and control over natural resources can be an additional contributing factor (Benjaminsen et al. 2009, Turner 2004).

The second line of thinking asserts that joining in conflict is the result of cost-benefit considerations. While participating in acts of violence or supporting armed groups may imply high individual costs (death, injury, imprisonment and so on.), people may still choose to participate because of the

\footnotetext{
${ }^{6}$ Resource conflicts or resource-related conflicts are social conflicts (violent or nonviolent) associated with both struggles to gain access to natural resources and struggles resulting from the use of natural resources (Turner 2004: 864).
} 
potential gains, such as improved socio-economic opportunities, access to valuable assets or loot (Collier and Hoeffler 1998, Keen 1998). The gains however may consist of protection or the fulfillment of basic economic needs as well (Justino 2009). Therefore, high levels of poverty may drive individuals into conflict especially when productive activities are scarce, unemployment is high and returns from agriculture work are low (Justino 2009). Those with poorer economic opportunitiesthe poor, the uneducated, the jobless, the landless, the dissocialized, the youth - are more likely to join criminal groups or rebel activity because they have nothing to loose but all to gain (Collier and Hoeffler 1998). Oppositely, not participating may be particularly costly because it raises suspicion or it excludes one from protection by armed groups and access to resources they control. Such costs may render it impossible to stay out (Kalyvas and Kocher 2007).

Thirdly, power determines the distribution of access to key resources and the potential to safeguard basic political, economic and social rights. Vulnerability and powerlessness result often from a political and economic process of neglect, exclusion or exploitation. Attention for power relations is therefore essential when studying resource scarcity conflicts and its underlying causes (Le Billon et al. 2000). Moreover, power may influence the inclination to conflictive behavior. Powerful individuals generally display less behavioral inhibition, they pay less attention to others and may exploit their power which makes it more likely they act in a self-interested way and transgress social norms (Keltner et al. 2003, Van Kleef et al. 2006).

At a fundamental level, conflict originates from individuals' behavior and their interactions with their immediate surroundings (Verwimp et al. 2009). While the literature tries to explain how incidences of conflict relate to resource scarcity, there is little evidence of the relation between the individual predisposition for conflictive behavior and water scarcity. This study will provide such evidence by making use of a framed field experiment, conducted with irrigators from semi-arid Tanzania, which replicates water appropriation dilemmas in common water flows under circumstances of water scarcity. More particularly, we want to know who is more inclined to engage in water scarcity conflicts. Three subsequent questions will guide our analysis. First, does water scarcity induce a reduction of extraction (the CPR thesis) or does it introduce competition (the resource scarcity conflict thesis)? 
Secondly, what is the profile of those that react with conflictive behavior to water scarcity? Are these the marginalized, the dissocialized, the poor, those with low human capital, those with little to loose or much to gain as the conflict literature presumes? Thirdly, individuals who are more inclined to react with conflictive appropriation behavior to water scarcity may be the ones that are more easily convinced to resort to more violent ways of competing for scarce resources if water scarcity would coincide with other factors conducive to violent conflict. That is why we will conclude by putting our findings in a political ecology perspective and evaluate to what extent circumstances in Tanzania are such that resource scarcity could engender violent conflict?

\section{Research design}

We study the effect of water scarcity on conflictive behavior in smallholder irrigation schemes in Tanzania where irrigation water is a seasonally scarce CPR principally governed by the user communities. The selected five irrigation schemes are located in the Rufiji river basin in the semi-arid low land areas of Mufindi district, Iringa region, Tanzania. Strong non-competition and reciprocity norms are essential tools for regulating the distribution of the common water flow in these irrigator communities. Yet some defy the norms and enter into appropriative competition with others. This however is badly looked upon and considered to be conflictive behavior. Disputes over water arise regularly, yet violent conflicts over water have been largely absent (Lecoutere et al. forthcoming).

We assume that users whom are more inclined to enter into appropriative competition when water is scarce despite the existence of non-competition norms would also be more easily convinced to engage in more violent ways of competing for scarce resources. And we want to know what characterizes these users. we use two types of data: data on irrigators' behavior in a framed field experiment and data on the irrigators' individual characteristics and their relative power status in their community.

The framed field experiment was designed to replicate real life dilemmas irrigators face when they appropriate water from a common water flow in circumstances of water abundance and of water scarcity. Appropriation from a common water flow is sequential and entails vertical downstream externalities (Cardenas et al. 2008). Consequently, appropriation does not necessarily affect the resource stock but mainly affects the remaining resource units for subsequent user(s). Furthermore, 
scarcity is not just a reduction of resource units per head but essentially entails there is an insufficient supply of resource units to fulfill the users' needs (UNDP, 2006:133). That is why our design differs from other experiments that replicate CPR dilemmas where the underlying concern is resource provision and where resource scarcity affects appropriation behavior because resource stocks are more rapidly depleted (e.g. Osés-Eraso and Viladrich-Grau 2007).

The dilemma in appropriation from common water flows with spatially fixed appropriators can be mimicked by a repeated dictator game. In the experiment, a participant who is randomly assigned an upstream water user is the 'proposer' and repeatedly determines a split of the available resource units. More specifically, she decides during how many hours to extract irrigation water from an available 12 hours. This is indicated on card that is passed on to the participant assigned downstream water user who is permanently paired to the upstream user. The downstream user is the 'responder' who receives the remainder. In reality however the downstream user is not a passive receiver. Hence, the ability to remain silent, to communicate appreciation, to communicate dissatisfaction or to call for a punishment through a mediator have been included. The latter implies a minor cost for the downstream user and a small fine for the upstream user. The downstream user's reaction is indicated on the same card that goes back to the upstream user. Thereafter, the subsequent round starts and the upstream user decides on water extraction another time and a new card goes to the downstream user for reaction, and so on. Participants were not informed about the number of rounds.

To asses the effect of water scarcity on appropriation behavior, the experiment includes five rounds in which water is abundant and ten rounds in which water is scarce. Under water abundance, total water availability is sufficient for both up- and downstream user to reach a threshold - set at four hours - that represents a critical water input required for irrigated agricultural production. Above the threshold payoffs rise with hours of water extracted; below the threshold payoffs are minimal. Water scarcity is mimicked by fixing the threshold at seven hours which renders it impossible for both up- and downstream users to reach above threshold payoffs. In addition payoffs per hour of water extraction 
are lower and increase only half as fast per extra hour. Information on payoffs per hours of water was available to up- and downstream users ${ }^{7}$.

At the end of the experiment, each participant received the sum of payoffs minus mediator fines or mediator costs if any. On average participants received 2460 TSH (=1.37 USD). In total, 13 sessions of the experiment were organized, each with a maximum of 14 randomly selected participants of the same irrigation scheme.

Secondly, we conducted an individual survey of 228 irrigators randomly selected from each of the five irrigation schemes, including all that participated in the experiment. The survey included questions on socio-economic characteristics, on networks and social capital, on irrigated agricultural production and on conflicts over irrigation water. Additionally, a participatory ranking exercise was organized to get a measure of irrigators' relative power status in the irrigation community based on the community members' perception (Laws et al. 2003). Social status - a strong positive correlate and a more commonly understood and unambiguous concept - was used as a proxy for power status ${ }^{8}$. In each of the five irrigation schemes, four randomly composed mixed groups ranked the irrigators who were identified on participatory drawn maps by putting irrigators' name cards on a ladder with four rungs. High (low) rungs represented high (low) social status. Each of the four rankings per irrigator was transformed into a score, equal to the value assigned to the rung - one to the lowest rung, four to the highest - divided by the number of rungs on the ladder. The mean of scores makes up our measure of irrigator's relative social status i.e. relative power status.

Finally, to put our findings into a larger, political ecology perspective, we discuss trends that drive up competition over water in Tanzania and potential exclusionary features of water governance institutions on the basis of secondary sources. Additionally, we assess inequalities in wealth, income

\footnotetext{
${ }^{7}$ All tools used both figures and symbols to ensure understanding by lowly educated people. Tools and instructions can be obtained on request.

${ }^{8}$ Social status is a collective judgment of the relative position of an individual in society based on her traits and assets and is an important source of power (Weiss and Fershtman 1998).

'Hadhi ya jamii' (status in society) and 'uwezo' (ability: economic ability but also ability to attain one's goals, to influence others) were used as Swahili translations for social status.
} 
opportunities, power, water or land access at the irrigation scheme level with the survey data and at the regional level by using National Sample Census of Agriculture 2002/2003 data (URT 2006).

\section{Empirical results}

In this section we will first discuss appropriation behavior in the experiment when water is abundant and the change in behavior when it becomes scarce. Thereafter, we will sketch a profile of who reacts with conflictive appropriation behavior to water scarcity by linking different responses to water scarcity to individual characteristics of the irrigators who participated in the experiment.

The framed field experiment consists of repeated dictator game. In fact, if (common knowledge of) narrow material self-interest is assumed, the only pure strategy equilibrium of the game would consist of the upstream user maximizing her payoff by appropriating all of the available water units. Yet such equilibrium has been refuted. Actually, the average proposed shares in dictator games range between 0.31 and 0.5 and are generally large in small-scale communities where strong egalitarian norms prevail (Camerer 2003, Henrich et al. 2004). Moreover, we framed the experiment and participants face dilemmas they know from real life. Therefore we expect social norms and social proximity, which are known to counter excessive extraction in CPR settings, will enhance fair behavior (Velez et al. 2009).

In the five rounds in which water is abundant in the experiment the average proposed share by the 78 upstream users is 0.52 . This corresponds to appropriation of less than half of the available hours of water, i.e. 5.73 hours (SD 2.01). This 'more than fair' behavior is probably motivated by the strong norms of non-competition that regulate water use in these irrigation schemes.

Introducing water scarcity, on the one hand, could induce competitive, selfish extraction behavior. This is what the thesis of resource scarcity conflicts would predict. On the other hand, the CPR thesis states that communities can overcome distributive conflicts over scarce resources with a suitable set of institutions. In line with this thesis Osés-Eraso and Viladrich-Grau (2007) and Rutte et al. (1987) have observed a reduction in CPR extraction in response to resource scarcity in their experiments.

Yet, in our experiment, irrigators do not reduce appropriation in response to water scarcity. The average proposed share in the ten rounds of water scarcity drops to 0.45 . On average upstream users 
now appropriate more than half of the available hours, i.e. 6.57 hours (SD 1.87). This is significantly more than under water abundance. Thus, in line with the resource scarcity conflict thesis and despite the strong non-competition norms regulating CPR use, water scarcity induces selfish appropriation behavior, which is considered conflictive appropriation behavior in these communities.

However, not all upstream users react to water scarcity in the same way. Actually, if we compare average appropriation levels under water abundance and water scarcity, we find that $28.21 \%$ of 78 upstream users react with conflictive appropriation to water scarcity by increasing from non-selfish to selfish appropriation levels (table 1: AVG). If we evaluate the shock effect of water scarcity by comparing the last abundance round (round 5) with the first scarcity round (round 6), we find that $37.18 \%$ reacts with conflictive appropriation to water scarcity (table 1: R5R6). Only a limited number of upstream users reduce from selfish appropriation levels in abundance to non-selfish levels in scarcity (AVG:3.85\%; R5R6:7.69\%). Others permanently behave in a selfish and conflictive way whether water is abundant or scarce. A relatively high proportion remains non-competitive throughout and appropriates in a non-selfish way (AVG:34.62\%; R5R6:37.18\%).

\begin{tabular}{|c|c|c|c|c|}
\hline & $\begin{array}{c}\text { Conflictive } \\
\text { reaction }\end{array}$ & $\begin{array}{l}\text { Permanently } \\
\text { conflictive }\end{array}$ & Reduce & $\begin{array}{c}\text { Permanently } \\
\text { non- } \\
\text { competitive }\end{array}$ \\
\hline Comparing averages & $28.21 \%$ & $33.33 \%$ & $3.85 \%$ & $34.62 \%$ \\
\hline Comparing last abundance round (R5) with first scarcity round (R6) & $37.18 \%$ & $17.95 \%$ & $7.69 \%$ & $37.18 \%$ \\
\hline
\end{tabular}

Water scarcity clearly induces different reactions among participants. Our aim is to know who would engage in water scarcity conflicts. Thus we seek an answer to our second question: What is the profile of those that respond to water scarcity with conflictive appropriation? Does the profile of those that enter into water scarcity conflict in the experiment confirm the hypotheses that people whom are most likely to join in conflict the poor, marginalized, dissocialized, with low human capital and with higher stakes?

To link the likelihood of reacting to water scarcity by conflictive behavior, reducing appropriation, persisting in conflictive or in non-competitive behavior to irrigators' individual characteristics we need to look at the change in appropriation behavior when water becomes scarce. Therefore, we estimate 
the $(\log )$ odds of making selfish appropriation decisions in the experiment using a binary logistic regression. The independent variables are individual and household characteristics of the participating irrigators (table 2: descriptive statistics). To asses the effect of water scarcity on the likelihood of selfish appropriation decisions on participants with different characteristics we interact each of the independent variables with the treatment effect, i.e. the dummy variable 'Scarcity'. This permits to calculate the likelihood of selfish appropriation behavior when water is abundant and when it is scarce (table 3). An irrigator with median characteristics can be used as a reference. This irrigator is a man who believes in fairness, has not experienced irrigation water shortages, is not a member of village government, does not belong to a minority religious group and lives in a food secure household with median wealth in terms of assets and landholding. His appropriation decisions are unsanctioned. The probability the reference irrigator makes a selfish appropriation decision when water is abundant (AB) in the experiment is $\mathrm{p}_{\mathrm{AB}}=.216$. The probability he makes a selfish appropriation decision when water is scarce ( $\mathrm{SC}$ ) is $\mathrm{p}_{\mathrm{SC}}=.329$ which is significantly higher ${ }^{9}$. Then the effect of the participants' individual characteristics on these probabilities can be assessed.

\begin{tabular}{|c|c|c|c|c|}
\hline In the population of participating upstream users: & Proportion & & & $\mathrm{N}$ \\
\hline Male & $67.9 \%$ & & & 78 \\
\hline Foodinsec & $41.0 \%$ & & & 78 \\
\hline Villgvt & $42.3 \%$ & & & 78 \\
\hline Watershort & $26.9 \%$ & & & 78 \\
\hline No_fair & $24.4 \%$ & & & 78 \\
\hline Min_reli & $30.8 \%$ & & & 78 \\
\hline Young & $29.5 \%$ & & & 78 \\
\hline No_edu & $19.7 \%$ & & & 76 \\
\hline Farmincome & $23.4 \%$ & & & 77 \\
\hline Low_power & $30.3 \%$ & & & 76 \\
\hline \multirow[t]{2}{*}{ High_power } & $30.3 \%$ & & & 76 \\
\hline & Mean & Median & SD & $\mathrm{N}$ \\
\hline Irrisize & 1.365 & 1.000 & 1.048 & 72 \\
\hline DevSQirrisize & 1.037 & .415 & 2.134 & 72 \\
\hline Assets1 & .045 & -.370 & 1.110 & 72 \\
\hline Assets2 & .005 & .232 & 1.027 & 72 \\
\hline
\end{tabular}

Table 2: Descriptive statistics of independent variables

In a second step we make the findings more concrete by calculating the effect of particular individual characteristics on the probability to react to water scarcity by conflictive appropriation, by reducing appropriation or by persisting in conflictive or in non-competitive appropriation. We do so by

\footnotetext{
${ }^{9}$ With $\mathrm{p}_{\mathrm{AB}}=\exp \left(\sum\left(\beta_{\mathrm{i}} \mathrm{X}_{\mathrm{i}}\right) /\left(1+\exp \left(\sum \beta_{\mathrm{i}} \mathrm{X}_{\mathrm{i}}\right)\right.\right.$ and $\mathrm{p}_{\mathrm{SC}}=\exp \left(\sum\left(\beta_{\mathrm{i}} \mathrm{X}_{\mathrm{i}}+\gamma_{\mathrm{i}}\left(\mathrm{X}_{\mathrm{i}} \mathrm{xSc}\right)\right) /\left(1+\exp \left(\sum\left(\beta_{\mathrm{i}} \mathrm{X}_{\mathrm{i}}+\gamma_{\mathrm{i}}\left(\mathrm{X}_{\mathrm{i}} \mathrm{xSc}\right)\right)\right)\right)\right.$.
} 
multiplying the probability of (non)selfish behavior in water abundance with the probability of (non)selfish behavior in water scarcity based on the regression estimates. For instance, the probability that the reference irrigator reacts to water scarcity with conflictive behavior is calculated by (1$\left.\mathrm{p}_{\mathrm{AB}}\right) \times \mathrm{p}_{\mathrm{SC}}$ and is .258 (table 4). His most likely reactions to water scarcity are persisting in noncompetitive behavior (.526). His reactions are less likely to consist of reducing appropriation (.145) and least likely to consist of persistent competition (.071). These probabilities can be calculated for irrigators with different characteristics. 


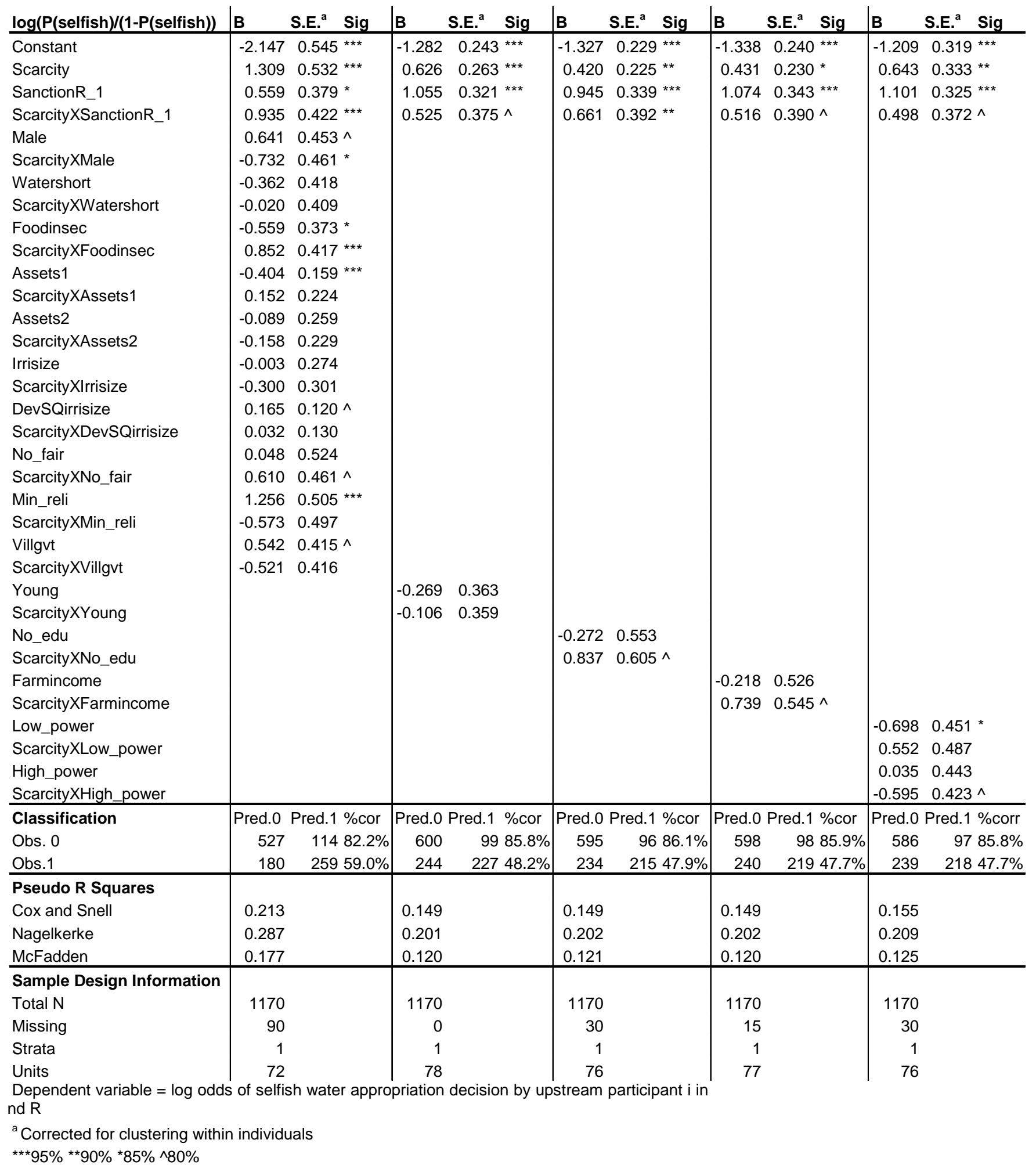

Table 3: Binary logistic regression estimating the likelihood of making selfish appropriation decisions when water is abundant and when it is scarce 
We now evaluate the effect of sanctions and of specific individual characteristics on appropriation behavior. First, if the upstream user has been sanctioned by the downstream user, i.e. received dissatisfied reaction or a punishment, for her appropriation decision in the previous round, the upstream user's appropriation decision is likely to be affected. Therefore we included a dummy SanctionR_1 as a control variable ${ }^{10}$. Contrary to expectations, if the upstream user was sanctioned in the previous round the likelihood of being selfish is significantly higher both when water is abundant and when it is scarce. Sanctioning provokes a counteraction rather than a correction of uncooperative behavior in the experiment, possibly because such adversarial reactions are unacceptable in these communities with a tradition of reconciliatory conflict settlement.

\begin{tabular}{|c|c|c|c|c|}
\hline & $\begin{array}{c}\text { Conflictive } \\
\text { reaction }\end{array}$ & $\begin{array}{c}\text { Permanently } \\
\text { conflictive }\end{array}$ & Reduce & $\begin{array}{c}\text { Permanently } \\
\text { non-competitive }\end{array}$ \\
\hline Effect of being female & 0.305 & 0.044 & 0.082 & 0.568 \\
\hline Effect of food insecurity & 0.343 & 0.054 & 0.082 & 0.521 \\
\hline Effect of larger irrigated plot $^{\mathrm{a}}$ & 0.258 & 0.071 & 0.145 & 0.526 \\
\hline Effect of larger squared deviation irrigated plot $^{\mathrm{a}}$ & 0.295 & 0.116 & 0.166 & 0.423 \\
\hline Effect of no belief in fairness & 0.372 & 0.103 & 0.114 & 0.412 \\
\hline Effect of membership of minority religion & 0.321 & 0.311 & 0.181 & 0.187 \\
\hline
\end{tabular}

a:Median+S.D. (see table 2)

Table 4: The effect of different individual characteristics on the probability of reacting to water scarcity with conflictive appropriation, persisting in conflictive appropriation, reducing appropriation or persisting in non-competitive appropriation

\footnotetext{
${ }^{10}$ Appropriation decisions are likely to be correlated within individuals and the downstream user's sanctioning behavior is a direct function of the upstream user's appropriation decision. One could thus argue that our models suffer from endogeneity problems similar to those encountered in dynamic panel data models. However, omitting the reaction of the downstream user in the previous round as an explanatory variable would induce an omitted variable bias. The standard solution to this problem to estimate the model in first differences and use suitably lagged levels of the endogenous variable as instruments (Bond 2002). This, however, is uninteresting as this deletes all time invariant variables from the model, which are key in this study. Yet the first decision by the upstream user can be considered to be exogenous, since we use experimental data, which eliminates the problems mentioned above (Stewart 2006). Moreover, any endogeneity bias in panel data disappears as $\mathrm{T}$ goes to infinity. The data used here comprises of 15 rounds which makes any endogeneity bias negligible.
} 
Secondly, gender ('Male') is expected to influence appropriation behavior in response to water scarcity because water values and community mechanisms to induce non-competitive appropriation behavior are different for men and women (Lecoutere et al. forthcoming). Moreover, the conflict literature associates a higher likelihood of conflictive behavior to men than to women. We observe that male participants are more likely to be selfish than women when water is abundant in the experiment. Yet, in reaction to water scarcity their likelihood to be selfish increases less than for women. Thus, while men are more competitive from the start, women are more likely to react with conflictive behavior to water scarcity than men $(=.305)$. Water may be more valuable to women for reasons of subsistence or they may anticipate of being allowed a larger share by the community to provide for pressing needs (Lecoutere et al., forthcoming).

Thirdly, the literature suggests the poor and uneducated are more likely to exhibit conflictive behavior. As a first indicator of poverty we included the dummy variable 'Foodinsec', which indicates that the participant's household has experienced food insecurity in the two years preceding the survey. Lack of education ('No_edu') is another indicator for poverty ${ }^{11}$. We find that poor participants are less likely than others to make selfish appropriation decisions when water is abundant but more likely to make selfish appropriation decisions when water is scarce. Both poverty indicators, food insecurity and lack of education, confirm this ${ }^{12}$. Possibly, if resources are abundant the poor abide strongly with noncompetition norms because their vulnerable position makes them highly susceptible to social pressure. But if resources such as water, which are probably vital for subsistence, are scarce the poor will enter into competition (Lecoutere et al. forthcoming). As a result and in line with expectations, the probability that the poor react with conflictive behavior to water scarcity is higher than for others (e.g. $=.343$ for food insecure participants).

Oppositely, wealth is expected to negatively affect conflictive behavior. Assets owned by the participants' household are an indication of wealth. The first wealth indicator represents mainly

\footnotetext{
${ }^{11}$ Lack of education is possitively correlated with food insecurity and with agriculture as the sole income. It is negatively correlated with all asset indicators.

${ }^{12}$ Having only income out of agriculture, which also relates to poverty, confirms this relation.
} 
household's wealth in livestock ('Assets1'), the second mainly housing quality and ownership of transport means ('Assets2') ${ }^{13}$. Other (relative) wealth indicators are the size of irrigated land and its (squared) deviation with the irrigation scheme's average ('Irrisize'; 'DevSQirrisize'). We do not however observe a great impact of wealth on appropriation behavior in abundance. The livestock wealth indicator negatively affects the likelihood of selfish appropriation in water abundance. A larger deviation from the irrigation scheme's average increases the likelihood of selfish appropriation decisions in abundance. Possibly it reduces incentives for cooperative behavior but not necessarily as a result of scarcity. Actually, wealth does not seem to affect appropriation behavior when water becomes scarce.

Fourthly, marginalization, a low degree of social ties and a weaker adherence to fairness norms are expected to enhance conflictive behavior in response to resource scarcity because social pressure and the deterrence effect of non-competition norms are reduced (Hayami 2009). A measure for lack of individual belief in fairness is based on the General Social Survey (GSS) question on fairness ('No_fair'): "Do you think most people would try to take advantage of you if they got a chance, or would they try to be fair?" (Karlan 2005:20) ${ }^{14}$. We observe that participants who lack belief in fairness are more likely to appropriate in a selfish way but only when water is scarce. This increases the likelihood that these participants react with conflictive behavior to water scarcity (=.372).

As an indicator of a low degree of social ties in the community we constructed dummy variables indicating membership of a religious group or tribe that includes less than one third of the irrigation schemes' population ('Min_reli'; 'Min_tribe') since social ties often coincide with religion or tribe in rural Tanzania. Additionally, minority religious groups and tribes suffer from unequal access to resources and power in the irrigation schemes (see discussion). Such exclusion from economic or

\footnotetext{
${ }^{13}$ We reduced information on seven different assets i.e. size of total landholding, size of irrigated plots, number of cows, whether the house is built with bricks, whether the house has an iron roof or roof tiles, ownership of bicycle and livestock value to two uncorrelated principal components. These explain $60 \%$ of the variability in the original seven variables. Both components are uncorrelated with landholding. (Livestock value is the total value of big and small livestock calculated using marketvalues at the time of the survey (www.lmistz.net and market prices recorded in Mufindi district, July 2008).

${ }^{14}$ Respondents expressed belief in fairness by referring to a scale going from low over moderate to high levels of fairness. Below moderate levels are taken as an indication of not believing in fairness.
} 
political opportunities may frustrate people and may create incentives for more conflictive behavior (Stewart 2000). We find that members of a minority religion are much more likely to make selfish appropriation decisions when water is abundant ${ }^{15}$. When water is scarce the likelihood of making selfish decisions rises as much as it does for others. Their reactions to water scarcity consist mainly of persisting or entering in competition. Irrigators with low degrees of social ties are more likely to exhibit conflictive appropriation behavior but not necessarily as a response to resource scarcity.

Fifthly, if stakes are higher we expect more conflictive behavior in response to water scarcity. The (relative) importance and value of irrigation water is expected to be higher if participants experienced irrigation water shortage in any one of the two dry seasons preceding the survey, if agriculture is their only source of income and if the percentage of irrigated land allocated to cash crops is larger (resp. 'Watershort'; 'Farmincome') ${ }^{16}$. The percentage of irrigated land allocated to cash crops did not have a significant effect on appropriation behavior and was dropped because of correlations with other variables. Possibly, irrigation water is equally highly valued by commercially oriented farmers as it is by subsistence farmers. Unexpectedly, our results show that having experienced water shortages does not make participants appropriate in a more selfish way, not even when water is scarce. Either this experience has not raised the value they allot to water, or they have learned not to respond with selfish behavior. But when participants only gain an income out of agriculture and irrigation water is of great importance for their livelihood, we observe an increased likelihood of selfish appropriation when water is scarce. Consequently, these participants are more likely to respond with conflictive behavior to water scarcity than others.

Sixthly, while youngster are assumed to be more inclined to conflictive behavior, we do not observe a higher likelihood of selfish appropriation by relatively young participants when water is abundant nor when it is scarce ('Young' indicates the participant is (more than) seven years younger than the

\footnotetext{
${ }^{15}$ We did not observe the same effect when participants are member of minority tribes, probably because at present religion binds people more than tribe in rural Tanzania (Toner 2008).

${ }^{16}$ Only gaining an income out of agriculture is also associated to poverty.
} 
irrigation scheme's average $)^{17}$. Possibly young people are more susceptible to social pressure to avoid competition in these communities.

Lastly, a political ecology perspective requires taking into account patterns of power and dependency that may influence irrigators' appropriation behavior. While the more powerful members of society may take advantage of their position and compete over scarce resources, the less powerful may be more careful in competing with others. Yet if powerlessness coincides with poverty or results from processes of exclusion, it may increase the likelihood of conflictive appropriation over scarce but vital resources. A relatively low (high) power status points to a relative power status that is more than -.14 lower (.16 higher) than the average in the irrigation community ('Low_power'; 'High_power') ${ }^{18}$. Membership of village government is another more direct measure for (decision making) power ('Villgvt').

We observe that participants with a relatively low power status are less likely to make selfish appropriation decisions when water is abundant than others ${ }^{19}$. When water is scarce their appropriation behavior is not significantly different. It follows that low power status people are more likely to react with conflictive behavior to water scarcity. On the one hand, a low power status may imply a vulnerable position in the community and force people to comply with non-competition norms. On the other hand, a low power status is also related to poverty. When water is scarce, the need to secure sufficient water for subsistence may therefore annul the (social) pressure to comply with norms. Oppositely and contrary to expectations, more powerful irrigators are not more inclined to compete over scarce resources than others ${ }^{16}$. In fact, they are more likely to react to water scarcity by reducing appropriation. This can be due to two reasons: their high power status may relate to wealth and therefore they do not need to secure a sufficient share of scarce resources. Or their higher power status encourages them to exhibit exemplary behavior. But a position in village government creates more

\footnotetext{
${ }^{17}$ Included separately to avoid multicollinarity.

${ }^{18}$ Relational patterns did not affect behavior in the experiment in a direct way as participants however were uninformed about their counterpart. The internalized awareness of one's relative position in the community however influences behavior in the experiment (Cardenas 2003). The variables are included separately to avoid multicollinarity.

${ }^{19}$ Others whom power status diverges less than -.14 and less than +.16 from the irrigation site's average power status.
} 
incentives for conflictive behavior in abundance. When water is scarce the likelihood of selfishness increases as much as it does for others.

By conclusion, the answer to our second question: Are those who are most likely to enter into conflict over scarce resources the poor, marginalized, dissocialized, with low human capital and with higher stakes? Yes, they are. The poor, the uneducated and those with an income only out of agriculture whom stakes in irrigation water are higher - are more likely than others to react with conflictive appropriation to resource scarcity in the experiment. Those that adhere less strongly to fairness norms also show a higher likelihood of conflictive reactions to resource scarcity. Marginalized irrigators with limited social ties behave in a more conflictive way as well but not necessarily as a reaction to resource scarcity. Yet, our observations also contradict some assumptions. In fact, male irrigators, young irrigators, irrigators who allot a high (commercial) value to water and powerful irrigator are not more likely than others to engage in conflict over scarce resources.

\section{Discussion}

In the previous section, we presented behavioral evidence of who is likely to engage in resource scarcity conflicts. We assume these may be the ones that are more easily convinced to join in more violent ways of competing for scarce resources in reality. The relation between resource scarcity and conflict however is complex and multilayered. That is why we will evaluate our findings in political ecology perspective and evaluate to what extent other factors conducive to resource scarcity conflict are present in Tanzania.

First, existing conflicting pressures between different users of Tanzania's water resources - such as domestic users, farmers, livestock keepers, industry and hydropower plants - may well exacerbate by climate change and increasing climate variability which have made rainfall more erratic (Maganga et al. 2002, Paavola 2008, Sokoni and Shechambo 2005). Within the small-scale irrigation sector, competition over water is ever increasing. Irrigated agriculture has become more attractive because rain-fed agriculture has become riskier and because it has gained importance for production of locally marketable crops, like tomatoes and onions (Kaswamila and Masuruli 2004, Shao et al. 2002). 
Secondly, water governance institutions in Tanzania entail potential marginalizing and exclusionary features which could contribute to conflicts over (increasingly) scarce resources. Despite the National Water Policy's good intentions, its arguments to use water in the most efficient and sustainable way and the principle of treating water as an economic good can endanger the entitlement to water of small scale users (URT 2002) ${ }^{20}$. Participation of small scale users at basin level water resource management is questionable. Moreover, small scale users are likely to pull the shortest string if competition over water arises since mostly they do not hold an official water right. At the level of the smallholder irrigation schemes, water use is largely regulated by more informal institutions but often elements of formal institutions are blended in. The flexible and pragmatic nature of these (blends of) institutions allows accommodating for different challenges posed by water appropriation and has aided to avoid disruptive and violent resource conflicts. But processes of marginalization and exclusion are at work. If distributive conflicts arise, low power status and female irrigators do not always have the capability or forsake their capability to engage in creative conflict solving and often they do not uphold their interests (Lecoutere 2010).

Thirdly, horizontal inequalities, marginalization of certain groups and their exclusion from access to resources are other factors that are conducive to resource scarcity conflicts. Such inequalities in wealth, power and resource access could aid mobilization for (resource scarcity) conflicts, especially when a higher likelihood for conflictive water appropriation concurs with such inequalities.

The poor - those who have no education, only gain income out of agriculture and experienced food insecurity - exhibited a higher likelihood to enter into conflict over scarce resources in the experiment and in reality they are marginalized with regard to water and land access and (decision making) power $^{21}$. Both at the irrigation schemes level and the regional level, the poor report significantly more

\footnotetext{
${ }^{20}$ NAWAPO serves as the reference even while it has not been fully incorporated into legislation yet.

${ }^{21}$ To check for inequalities at the irrigation scheme level, we use the survey sample here and we check for correlations in each of the five irrigation schemes $(\mathrm{N}=228)$. Note that these variables were not significantly correlated in the sample of experiment participants we used for the logistic regression.
} 
problems of water shortage ${ }^{22}$. The poor have smaller landholdings and a lower proportion owns their land, while the wealthy have significantly larger (irrigated) landholdings ${ }^{23}$. Moreover, poverty negatively correlates with relative power status in the irrigator community, while wealth positively correlates with it. There is a significantly lower proportion of village government members among the poor and a higher proportion among the wealthy in the irrigation schemes.

Next, there is experimental evidence that members of minority religious groups are more inclined to conflictive appropriation both when water is abundant and when it is scarce. Besides, mobilization to join in (resource scarcity) conflicts is most effective if inequalities in economic opportunities, resource access or political participation coincide with cultural, ethnic or religious differences (Stewart 2000). Such inequalities are present in the studied irrigation schemes. Actually, members of minority religions and members of minority tribes report significantly more water shortage problems. But in some irrigation schemes they can be considered wealthier in terms of livestock and housing quality. Members of minority tribes, however, have smaller (irrigated) landholdings in some irrigation schemes.

While we did not observe differences in reactions to water scarcity in the experiment between youth and older irrigators, between (traditional) government members and others, between lifetime residents and those who immigrated to the village, inequalities in wealth, water and land access and (decision making) power exist along these lines. While young irrigators are less wealthy in terms of livestock and housing quality, they have smaller landholdings and less own their land ${ }^{24}$. These relations with are confirmed at the regional level, except for housing quality. There is a significantly lower proportion of village government members among the young. Probably a persistent cultural fact that reserves leadership for men of certain age deprives the young (and women) of the capability to participate in

\footnotetext{
${ }^{22}$ Definition of water shortage problems at the irrigation scheme: too little water for farming in the irrigation scheme in any of the two dry seasons preceding the survey. At the regional level: drought was the main reason for a difference between the total area planted and harvested (irrigated or not).

${ }^{23}$ The wealthy are those who own cows, own a house built with bricks or iron roofing or have a higher than average asset holding in terms of livestock, housing quality and transport means.

${ }^{24}$ Plot division at heritage is probably one of the causes of problematic land access for youth involved in agriculture.
} 
decision making. Furthermore, irrigators whom are member of village government are generally wealthier in terms of livestock and housing quality and they have larger landholdings. Lifetime residents however do not seem privileged. There is no relation to wealth, government membership, water or land access.

By conclusion we answer the third research question: viewed from a political ecology perspective, are circumstances in Tanzania such that resource scarcity could engender conflict? Yes, they are. Water scarcity is expected to increase. At the same time commercialization of irrigated agriculture raises the value of water. De facto, water governance institutions entail exclusionary elements. Additionally, those who are more inclined to conflictive water appropriation in reaction to water scarcity in the experiment - the poor, the marginalized and the dissocialized - suffer from real economic and political inequalities. Such inequalities could form a basis for mobilization for more violent ways of competing for scarce resources.

Still, we do not want to raise suspicion that the poor and the marginalized will soon engage in resource scarcity conflicts in Tanzania. To date there have been few incidences of disruptive or violent resource scarcity conflicts in Tanzania. The relatively well functioning water governance institutions with good intentions and the strong egalitarian and peace minded norms in Tanzania reduce the threat of resource scarcity conflicts. Yet, the rising competition over scarcer water resources, the exclusionary features of water governance institutions and the concurrence of real economic and political marginalization with a higher likelihood of conflictive water appropriation in response to scarcity could be conducive to resource scarcity conflicts. Therefore, care should be taken and policy measures should ease these factors conducive to water scarcity conflicts. 


\section{References}

Benjaminsen, T., Maganga, F., Abdallah, J., 2009. The Kilosa Killings: Political ecology of a farmerherder conflict in Tanzania. Development and Change 40(3), 423-445.

Bogale, A., Korf, B., 2007. To share or not to share? (non-)violence, scarcity and resource access in Somali Region, Ethiopia. The Journal of Development Studies 43(4), 743-765.

Bond, S., 2002. Dynamic panel data models: A guide to micro data methods and practice. CEMMAP working paper CWP09(02). London: Centre for microdata methods and practice

Camerer, C., 2003. Behavioral Game Theory: Experiments in Strategic Interaction. Princeton University Press, Princeton.

Cardenas, J.C., 2003. Real wealth and experimental cooperation: experiments in the field lab. Journal of Development Economics 70(2), 263-289.

Cardenas, J.C., Carpenter, J., 2004. An inter-cultural examination of cooperation in the commons. Working paper, Department of Economics, Middlebury College.

Cardenas, J.C., Janssen, M., Bousquet, F., 2008. Dynamics of rules and resources: Three new field experiments on water, forests and fisheries, in: List, J., Price, M. (Eds.), Handbook on Experimental Economics and the Environment. Edward Elgar Publishing.

Collier, P., Hoeffler, A., 1998. On economic causes of civil war. Oxford Economic Papers 50, $563-$ 573.

de Kwaadsteniet, E., van Dijka, E., Wita, A., de Cremer, D., 2006. Social dilemmas as strong versus weak situations: Social value orientations and tacit coordination under resource size uncertainty. Journal of Experimental Social Psychology 42(4), 509-516.

Gleditsch, N., 2001. Resource and Environmental Conflict: The State-of-the-Art, in: Petzold-Bradley, E., Carius A., Vincze, A. (Eds.), Responding to Environmental Conflicts: Implications for Theory and Practice. Kluwer Academic Publishers, Dordrecht, pp. 53-66. 
Hayami, Y., 2009. Social Capital, Human Capital and the Community Mechanism: Toward a Conceptual Framework for Economists. Journal of Development Studies 45(1): 96-123.

Henrich, J., Boyd, R., Bowles, S., Camerer, C., Fehr, E., Gintis, H., 2004. Foundations of human sociality: Economic experiments and ethnographic evidence from fifteen smallscale societies. Oxford University Press.

Homer-Dixon, T., 1994. Environmental Scarcities and Violent Conflict: Evidence from Cases. International Security 19(1), 5-40.

Homer-Dixon, T., 1999. Environment, scarcity and violence. Princeton University Press, Princeton.

Justino, P., 2009. Poverty and Violent Conflict: A Micro-Level Perspective on the Causes and Duration of Warfare. Journal of Peace Research 46(3), 315-333.

Kalyvas, S., Kocher, M., 2007. How 'Free' is Free-Riding in Civil Wars? World Politics 59(2), 177216.

Kaplan, R., 1994. The coming anarchy: how scarcity, crime, overpopulation and disease are threatening the social fabric of our planet. The Atlantic Monthly, February, 44-76.

Karlan, D., 2005. Using Experimental Economics to Measure Social Capital and Predict Real Financial Decisions. American Economic Review 95(5): 1688-1699.

Kaswamila, A., Masuruli, B., 2004. The Role of Traditional Irrigation Systems in Poverty Alleviation in Semi-Arid Areas: The Case of Chamazi in Lushoto District, Tanzania. REPOA Research Report 04(3), Dar es Salaam.

Keen, D., 1998. The economic functions of violence in civil wars. Oxford University Press, Oxford.

Laws, S., C. Harper and R. Marcus. 2003. Research for Development. A Practical Guide. Sage publications. 
Le Billon, P., Macrae, J., Leader, N., East, R., 2000 The Political Economy of War: What Relief Agencies Need To Know. HPN Network Paper 33. ODI, London.

Le Billon, P., 2001. The Political Ecology of War: Natural Resources and Armed Conflict. Political Geography 20, 561-584.

Lecoutere, E., 2010. Institutions Under Construction: Resolving Resource Conflicts in Tanzanian Irrigation Schemes. MICROCON Research Working Paper 23, Brighton.

Lecoutere, E., D’Exelle, B., Van Campenhout, B., forthcoming. Gender, power and common pool resources: Behavioral evidence from Tanzanian small-holder irrigation systems.

Maganga, F., Butterworth, J. Moriarty, P., 2002. Domestic water supply, competition for water resources and IWRM in Tanzania: a review and discussion paper. Physics and Chemistry of the Earth 27, 919-926.

Osés-Eraso, N., Viladrich-Grau, M., 2007. Appropriation and concern for resource scarcity in the commons: An experimental study. Ecological Economics 63(2-3), 435-445.

Ostrom, E., 1990. Governing the Commons: The Evolution of institutions for collective action. Cambridge University Press, New York.

Paavola, J., 2008. Livelihoods, vulnerability and adaptation to climate change in Morogoro, Tanzania. Environmental Science \& Policy 11(7), 642-654.

Peluso, N., Watts, M., 2001. Violent environments, in: Peluso N., Watts, M. (Eds.), Violent Environments. Cornell University, Ithaca, pp. 3-38.

Rutte, C., Wilke,H., Messick, D., 1987. Scarcity or abundance caused by people or the environment as determinants of behavior in the resource dilemma. Journal of Experimental Social Psychology 23, $208-216$. 
Shao, F., Nyomora, A., Mlay, E., Kasunga, N., 2002. Study on the horticulture development in Tanzania. Ministry of Agriculture and Food Security, Dar es Salaam. www.kilimo.go.tz/publications/swahili docs/Cps docs/Horti Final Report.pdf (accessed 9 October 2009).

Singleton, S., 2007. Managing Pacific Salmon: The role of distributional conflicts in Coastal Salish Fisheries, in: Baland, J., Bardhan, P., Bowles, S. (Eds.), Inequality, Cooperation and Environmental Sustainability. Princeton University Press, Princeton, pp. 131-158.

Sokoni, C., Shechambo, T., 2005. Changes in the upland irrigation system and implications for rural poverty alleviation. A case of the ndiwa irrigations system, West Usumbara mountains, Tanzania. REPOA Research Report, 05(1), Dar es Salaam.

Starr, J., 1991. Water Wars. Foreign Policy (Winter), 17-36.

Stewart, F., 2000. Crisis Prevention: Tackling Horizontal Inequalities, Oxford Development Studies $28(3), 245-262$.

Stewart, M., 2006. A Stata program for the Heckman estimator of the random effects dynamic probit model. www2.warwick.ac.uk/fac/soc/economics/staff/academic/stewart/stata/redprobnote.pdf (accessed 20 May 2010)

Toner, A., 2008. 'I prayed and God gave me this car'- the interaction of religion, personal power and hierarchy in Uchira, Tanzania, Paper presented at the Religion, Social Exclusion and Development Seminar, University of Birmingham January 22, Birmingham, UK.

Turner, M., 2004. Political ecology and the moral dimensions of 'resource conflicts': the case of farmer-herder conflicts in the Sahel. Political Geography 23, 863-889.

UNDP, 2006. Human Development Report 2006. Beyond scarcity: Power, poverty and the global water crisis. United Nations Development Programme. 
United Republic of Tanzania (URT), 2002. National Water Policy. Ministry of Water and Livestock Development, Dar es Salaam.

United Republic of Tanzania (URT), 2006. National Sample Census of Agriculture 2002/2003, Tanzania. National Bureau of Statistics, Dar es Salaam.

Velez, M., Stranlund, J., Murphy, J., 2009. What motivates common pool resource users? Experimental evidence from the field. Journal of Economic Behavior and Organization 70(3), 485-497. Verwimp, P. Justino, P., Brück, T., 2009. The Analysis of Conflict: A Micro-Level Perspective. Journal of Peace Research 46(3), 307-314.

Weiss, Y., Fershtman, C., 1998. Social status and economic performance: a survey. European Economic Review 42, 801-820.

Welsch, H., 2008. Resource abundance and internal armed conflict: Types of natural resources and the incidence of 'new wars'. Ecological Economics 67, 503-513. 